\title{
Consultant Contract Negotiations
}

\author{
Lora Phillippe \\ Project Manager \\ Vincennes District INDOT
}




\section{Goals For This Presentation}

- Provide knowledge and a since of comfort when negotiating consultant contracts

- Supply tools and tips for the financial negotiations

- INDOT Local Public Agency webpage: www.in.gov/indot/2390.htm

- Help to insure you are receiving/giving the proper amount of technical support throughout your project

- Create a good start for a smooth project development process and successful project completion.

- Utilize the tax payers dollars to the best of your ability. 


\section{Ready to Negotiate the Consultant Contract}

- Applied for federal funding

- Awarded CN funds

- Posted an Request for Proposal (RFP)

- Scored the Letters of Interests (LOI's)

- INDOT approved your scoring documents

**You are ready to start the negotiation process $* *$ 


\section{First Steps...Getting Off To A Strong Start}

COMMUNICATE....COMMUNICATE....COMMUNICATE....COMMUNICATE

- Reach out to your selected firm

- Know who your point of contact is

- Discuss project details/ intent of the project

- Discuss schedule and budget

- ASK QUESTIONS 


\section{Local Independent Estimate}

According to the LPA Guidance Document https://www.in.gov/indot/files/LPA\%20Gui dance\%20Document.pdf

5-5.02 Independent Estimate

- Prior to receipt or review of the selected consultant's cost proposal, the LPA shall prepare a detailed independent estimate with an appropriate breakdown of the work by labor hours, types or classifications of labor required, other direct costs, and consultant's fixed fee for the defined scope of work. The independent estimate shall serve as the basis for negotiation.
- Helps the LPA understand the scope of their project

- Creates a starting point for negotiations with the selected consultant

- Proves to Federal Hwy that the LPA has understanding and ownership of their project 


\section{Reviewing $1^{\text {st }}$ Draft of Agreement}

- LPA-Consultant Contract Review Checklist

- INDOT Local Public Agency webpage: www.in.gov/indot/2390.htm

- Local Public Agency Consultant Information

- Local Public Agency Program Consultant Information

- Forms \& Tools

- LPA Consultant Contract Review Checklist - Effective 8/3/18

- Checklist breaks down the different sections of the agreement and provides specific items to review.

- Several items are mandatory

- Latest INDOT boilerplate

- Specific project information required

- Certain days allowed for certain activities 
a. Itemization of task elements with estimated hours by employee classification.

b. Cost calculations show the overhead rate and profit rate has been applied

Local Public Agency: Click here to enter text.

Des. No.: Click here to enter text.

Project Description: Click here to enter text.

Consultant Name: Click here to enter text.

1. Review the contract document

a. Verify that the draft contract is consistent with the latest INDOT boilerplate.

b. Verify that the contract description, Des. number and scope of work is within the parameters described in the
RFP advertisement and in SPMS.

c. Verify that the maximum compensation amount shown on page one matches the amount shown in Appendix
D.

d. Verify that Section 23 of the draft contract includes proper addresses for the LPA and for the consultant.

e. Verify that the signature page contains the names and titles for either the Board of County Commisgioners

2. $\square$ Verify Appendix "C" of construction inspection contracts indicates the Final Construction Records is to be
submitted within 45 days of the contractors last day of work.

3. Verify the Appendix " $D$ " compensation method is appropriate for the scope of work

a. Construction inspection services should be paid for on a negotiated hourly billing rate basis.

b. Other types of services may be paid for on a lump sum basis, cost plus fixed fee basis, unit price basis or

c. Cost plus percent of cost compensation is not allowed on any consultant contracts.

d. See the INDOT Professional Services Contract Administration Manual for more information on the compensation

Profesional Services Contract Administration Manual.pdf

4. Verify the consultant has provided a copy of the lead consultant's prequalification letter showing their approved overhead rate.

6. Analyze the Consultant Fee Proposal.

a. Confirm the task elements are relevant to the scope of work.

b. Confirm the proposal does not exceed the Escalation Values for INDOT Consultant Contracts. INDOT uses the Bureau of Labor and Statistics Employment Cost Index (LCI) to determine appropriate escalation values. Hollyowing c. Confim the overhead rate used in the fee proposal is consistent with or lower than the rate shown in the
consultant's prequalification letter.

d. Confirm, to the extent possible, major task element and overall cost totals are not excessive

7. If the contract is for Construction Inspection, is an Enginear's Assignment letter attached?

a. $\square$ Not Applicable

b. Engineer's Assignment is attached

ERC Simature: Date:

Printed Name: 


\section{Consultant Review Checklist....Section 1}

1. Review the contract document:

a. $\square$ Verify that the draft contract is consistent with the latest INDOT boilerplate.

b. $\square$ Verify that the contract description, Des. number and scope of work is within the parameters described in the RFP advertisement and in SPMS.

c. Verify that the maximum compensation amount shown on page one matches the amount shown in Appendix

d. $\square$ Verify that Section 23 of the draft contract includes proper addresses for the LPA and for the consultant.

e. Verify that the signature page contains the names and titles for either the Board of County Commigsioners, City Board of Public Works and Safety or the Town Board, as appropriate.
- The most current INDOT boilerplate can be found on the INDOT Local Public Agency website: www.in.gov/indot/2390.htm

- Local Public Agency Consultant Information

- Local Public Agency Program Consultant Information

- LPA Contracts

- LPA Consultant Boilerplate Contract

- All contracts MUST have the DES\# and scope of work listed on the contract.

- Verify all fee totals are consistent throughout the contract. 


\section{Consultant Review Checklist...Section 2}

- Only pertains to Construction

2. $\square$ Verify Appendix " $\mathrm{C}$ " of construction inspection contracts indicates the Final Construction Records is to be gubmitted within 45 days of the contractors last day of work. Inspection Contracts. 


\section{Consultant Review Checklist...Section 3}

3. $\square$ Verify the Appendix " $D$ " compensation method is appropriate for the scope of work.

a. Construction inspection gervices should be paid for on a negotiated hourly billing rate basis.

b. Other types of services may be paid for on a lump sum basis, cost plus fixed fee basis, unit price basis or negotiated billing rate basis.

c. Cost plus percent of cost compensation is not allowed on any consultant contracts.

d. See the INDOT Professional Services Contract Administration Manual for more information on the compensation methods. The manual is available at:

http://www.in.gow/indot/files/Professional Services Contract Administration Manual.pdf
- INDOT Local Public Agency Webpage: www.in.gov/indot/2390.htm

- Local Public Agency Consultant Information

- Local Public Agency Program Consultant Information

- Related Webpages

- Consultants/Pre-Construction Proposals \& Contracts

- Contract Compensation Information

$\checkmark$ Profit Matrix and Worksheet

$\checkmark$ Current Real Estate Fee Schedules

$\checkmark$ State Travel Policy/Reimbursement Rates

* Estimated time tables for Environmental Services

- Preliminary Engineering Cost $=15 \%-20 \%$ of CN cost 


\section{Profit Calculation Example}

Sign Modernization Project

- Programmatic Categorical Exclusion

INDOT Consultant Contracts Profit Calculation Worksheet

- No R/W

- No Utilities

- Total Project Cost \$1,200,000.00

- 3 years development

- $184 \%$ overhead rate

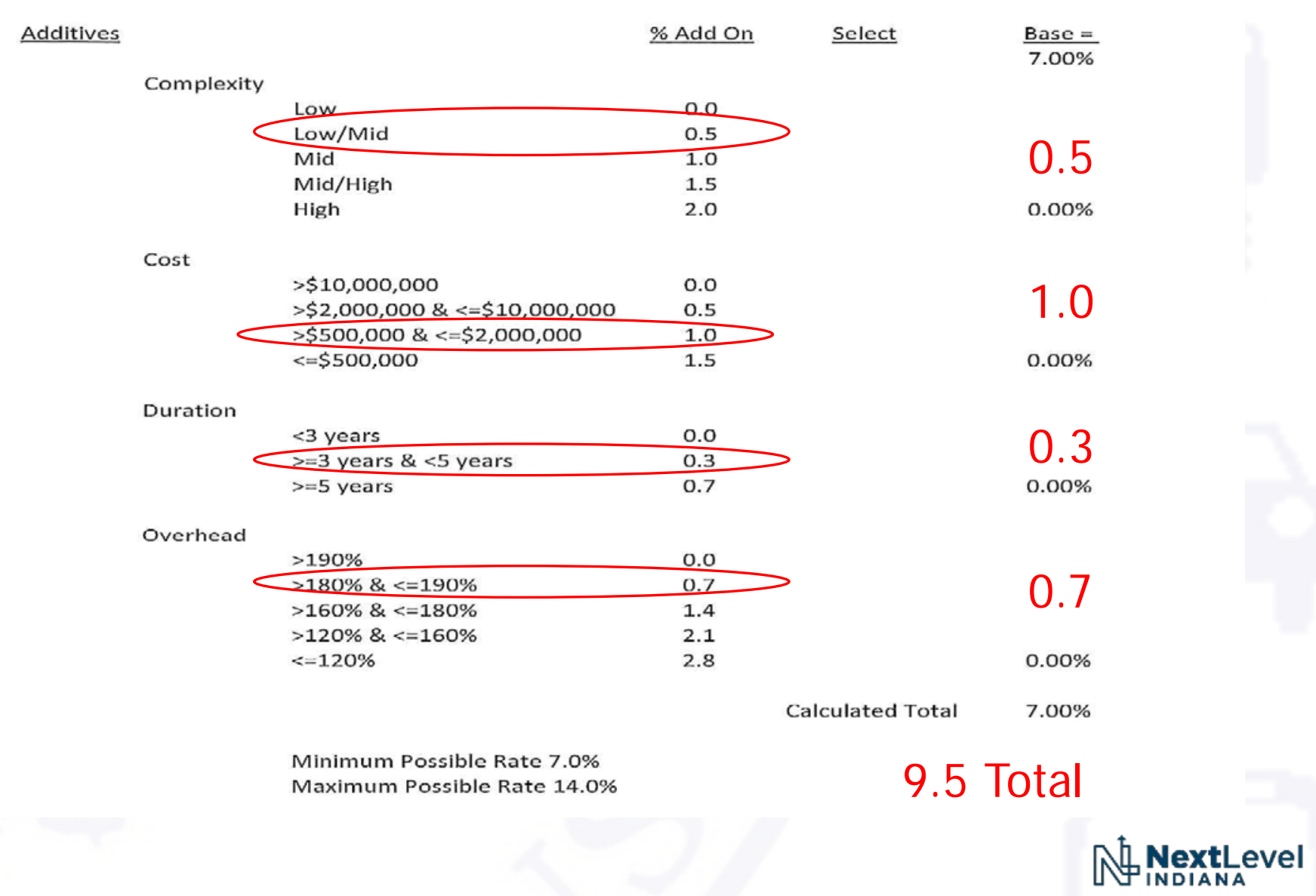


REAL ESTATE SERVICES FEE SCHEDULE

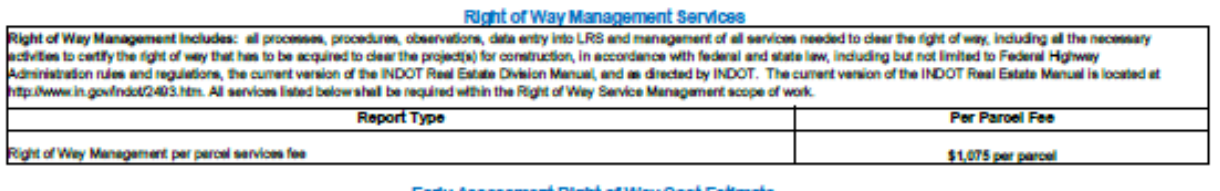

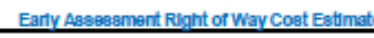

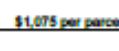

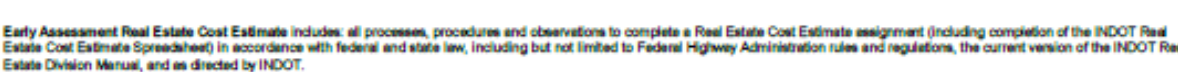

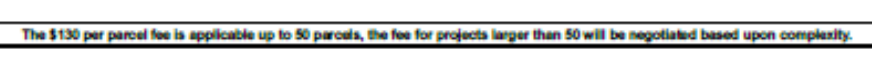

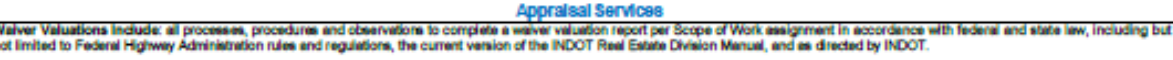

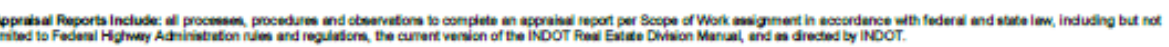

\begin{tabular}{|c|c|}
\hline Roport Tipos & Por Parroel Foo \\
\hline 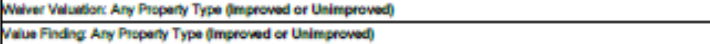 & $\frac{515}{51300}$ \\
\hline 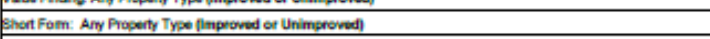 & 52.900 \\
\hline 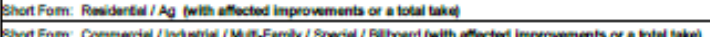 & 5010 \\
\hline 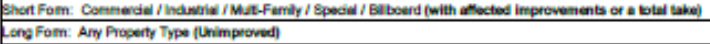 & $\frac{4350}{51200}$ \\
\hline 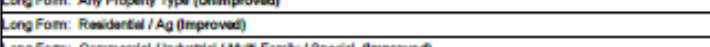 & $\frac{2,200}{4300}$ \\
\hline 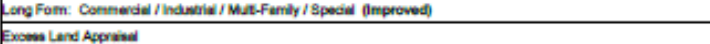 & $\begin{array}{lll}519750 \\
5615\end{array}$ \\
\hline 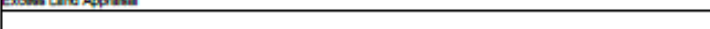 & \\
\hline
\end{tabular}

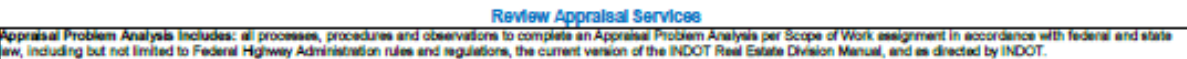

\begin{tabular}{|c|c|}
\hline Report Typo & Par Pastol Foo \\
\hline 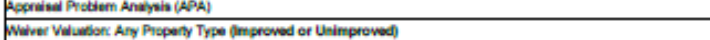 & 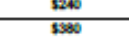 \\
\hline 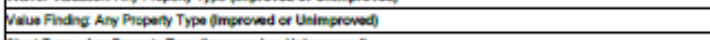 & 5020 \\
\hline 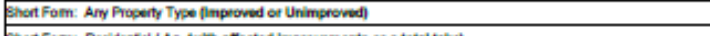 & 51220 \\
\hline 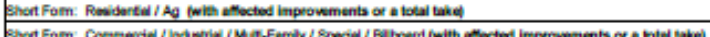 & $\frac{5.1058}{1000}$ \\
\hline 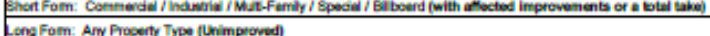 & $\frac{10.050}{15.158}$ \\
\hline 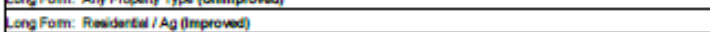 & 12000 \\
\hline 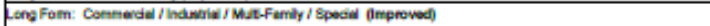 & \\
\hline
\end{tabular}

Buyling services

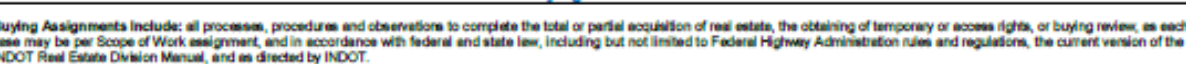

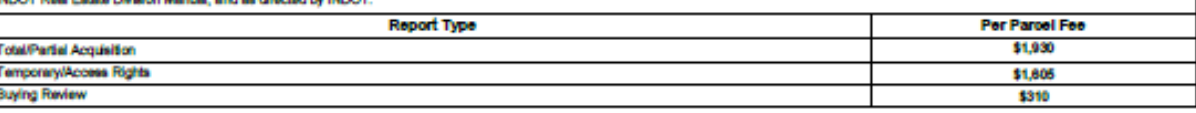

Relocation Serilcose

\begin{tabular}{|c|c|c|}
\hline \multicolumn{3}{|c|}{ 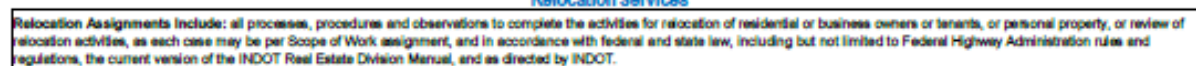 } \\
\hline Foport Type & Paymbers sohodulo & \\
\hline 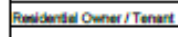 & 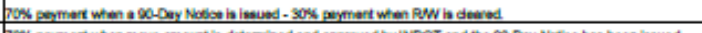 & 39085 \\
\hline 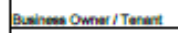 & 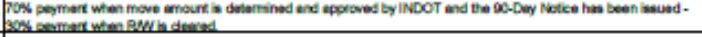 & 23.005 \\
\hline moned propery andy & 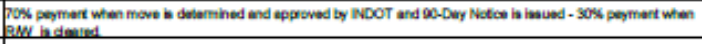 & s.6.615 \\
\hline 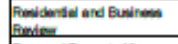 & 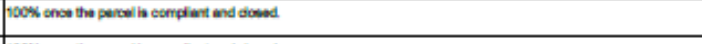 & s.,075 \\
\hline 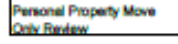 & 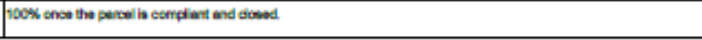 & \$10 \\
\hline
\end{tabular}

N\$N NextLevel

Renseb: : Mreon 


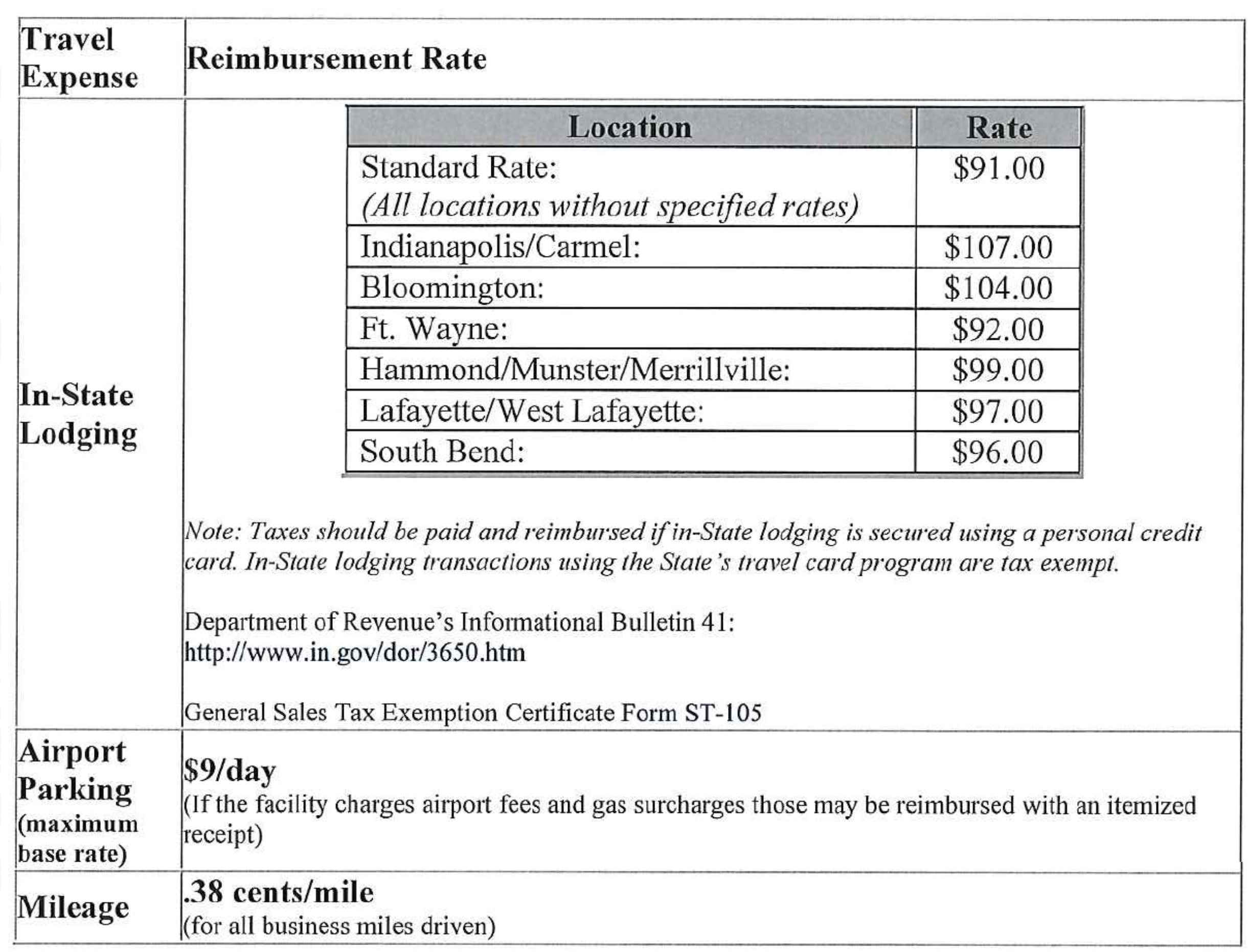


Environmental Working Times Table

* Please note...the hours listed below are to be used as the estimated average when reviewing the hours required per task. INDOT understands that the hours can vary considerably depending on the complexity of the project and other factors.

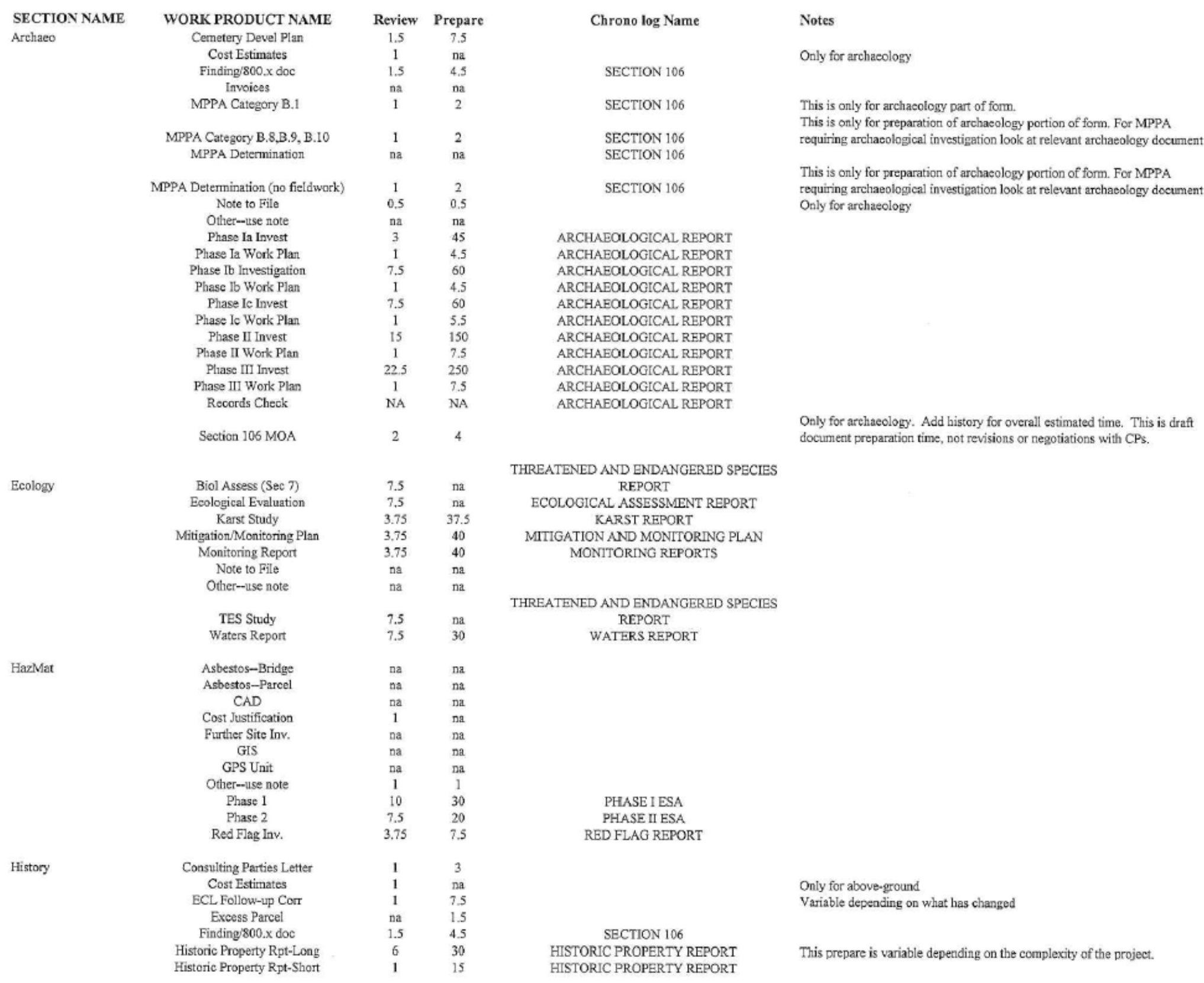

$\begin{array}{ccc}\text { WORK PRODUCT NAME } & \text { Review } & \text { Prepare } \\ \text { Cemetery Devel Plan } & 1.5 & 7.5\end{array}$

Cemetery Devel Plan
Cost Estimates

Finding/800 $x$ doc

Finding $/ 800 x$
Invoices

MPPA Category B.1

MPPA Category B.8,B., B. B.10

MPPA Deternination

MPPA Determination (no fieldwork)

Note to File
Other-wise note

Drese 10

Phase It Investigation

Phase It Work Plan

Phase Ic Invest
Phase Ic Work Plan

Phase Ic Work Plan
Phase II Invest

Phase II Work Plan

Plase III Invest
Phase III Work Plan

Phase III Work Plan
Records Check

Section 105 MOA

Ecoloagy

Biol Assess ( $(\mathrm{Sec} 7)$
Ecological Evaluation

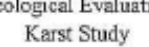

Karst Study
Mitigation/Monitoring Plan

Monitoring Report
Note to Fiple

Note to File
Other-use note

TES Study
Waters Report

HazMat

Asbestos-Bridge

Asbestos-Parcel
CAD

Cost Justification

Further Site Inv.

GIS
GPS Unit

Other-use note

\begin{tabular}{l} 
Phase 1 \\
Phase 2 \\
\hline
\end{tabular}

Red Flag Inv.

History

Consulting Parties Letter

Cost Estimates
ECL Follow-up Corr

Excess Parcel

Historic Property Rpt-Long
Historic Property Rpt-Shourt

Chrono $\log$ Name

SECTION 106

SECTION 106

SECTION 106

SECTION 106

ARCHAEOLOGICAL REPORT

ARCHAEOLOGICAL REPORT

ARCHAEOLOGICAL REPORT

ARCHAEOLOGICAL REPORT

ARCHAOLOCALI REPT

ARCHAEOLOGCGICAL REPORT

ARCHAEOLOGICAL REPORT

ARCHAEOLOGICAL REPORT

ARCHAEOLOGICAL REPORT

THREATENED AND ENDANGERED SPECIES

REPORT
ECOLOGICAL ASSESSMENT REPORT

MITIGATION AND MONITO

MONITORING REPORTS PLAN

TREATENED AND ENDANGERED SPECIES$$
\begin{aligned}
& \text { REPORT } \\
& \text { WATERS REPORT }
\end{aligned}
$$

PHASE I ESA

RED FLAG REPORT

\section{Notes}

Only for archaeology

This is only for archacology part of form.

This is only for preparation of archacology portion of form. For MP?A

This is only for preparation of archaeology portion of form. For MPPA

requiring archaeological investigation look at relevant archaeology documen
Only for archaeeology

Only for archaeelogy. Add bistory for overall estimated time. This is drat 


$$
\begin{aligned}
& \text { Section } 106 \text { MOA } \\
& \text { Section 4(f) }
\end{aligned}
$$

SECTION 106

HISTORIC PROPERTY SECTION 4(F)

Air Quality Analysis

$$
\text { CE1 }
$$

CE3
CE4

Commitments
Cost Justification EA

Envt Cons Fon

Excess Parcel

Noise Analysis

Note to File

Other-use note

Plan Review
Programmatic $\mathrm{CE}$
Revaluation

Revaluation
(Scoping Eng. ONLY)

Section $4(f)$

Section $4(f)$ Individual

State CE/EA
S
CE DOCUMENTS

CE DOCUMENTS

CE DOCUMENTS

EA DOCUMENTS

EIS DOCUMENTS

NOISE STUDY

CE DOCUMENTS

CE DOCUMENTS

WATERWAY PERMIT

WATERWAY PERMTS

WATERWAY PERMIT

WATERWAY PERMIT

WATERWAY PERMITS

WATERWAY PERMIT

WATERWAY PERMITS

WATER WAY PERMITT

LANDSCAPE DESIGN

WATER WAY PERMIT WATER WAY PERMITS

LANDSCAPE DESIGN

LANDSCAPE DESIGN
LANDSCAPE DESTGN
* Where one application will be used to apply for botit the 404 and 401 permits the hours stould only be counted one time. Also consider overlapping

information between the 404/401 and CIF permit applications as an opportumin to reduce hours. There may also only be one 404/401 application but multiple Specialist tey are required for each crossing Consutt with the distiot Permin 


\section{Consultant Review Checklist...Section 4, 5 \& 6}

4. $\square$ Verify the consultant has provided a copy of the lead consultant's prequalification letter showing their approved overhead rate.

5. Verify the consultant has provided a fee proposal and the fee proposal includes the following:

a. $\square$ Itemization of task elements with estimated hours by employee classification.

b. $\square$ Cost calculations show the overhead rate and profit rate has been applied

6. Analyze the Consultant Fee Proposal.

a. Confirm the task elements are relevant to the scope of work.

b. Confirm the proposal does not exceed the Escalation Values for INDOT Consultant Contracts. INDOT uses the Bureau of Labor and Statistics Employment Cost Index (ECI) to determine appropriate escalation values. INDOT's guidelines are available under the Contract Compensation Information section at: http://www.in.gov/indot $/ 2730 . \mathrm{htm}$

c. $\square$ Confinm the overhead rate used in the fee proposal is consistent with or lower than the rate shown in the consultant's prequalification letter.

d. $\square$ Confirm, to the extent possible, major task element and overall cost totals are not excessive.

\section{Consultants Please Provide}

- Detailed fee justification

- Also for sub consultants

- Consultants prequalification letter showing approved overhead rate

- Prequalified work type certification 


\section{Consultant Review Checklist...Section 7}

7. If the contract is for Construction Inspection, is an Engineer's Assignment letter attached?

a. $\square$ Not Applicable

b. Engineer's Assignment is attached.
Example Engineer Assignment letter (Should be printed on LPA's letterhead)

Date

Name and address of District contact person

Re: Des. No.

Project Location:

Dear Contact Person,

Mr./Ms. full time direct control of the project, and will follow the established procedures of the Indiana Department of Transportation (NDDOT) in the discharge of these duties and will be working under the supervision of the INDOT District

The Project Representative will utilize the services of the following personnel: Assistant Project Supervisor

Inspector

Inspector

4. Inspector

5. Project Manager

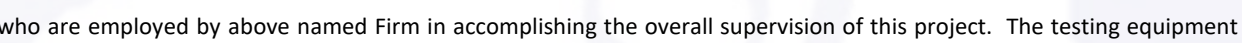
shall be provided by the named Firm as required.

We shall maintain all books, documents, paper, accounting records and other evidence pertaining to the cost incurred and shall make such materials available at their respective offices at all reasonable times during the contract period and for three (3) years from the date of final payment. The Federal Highway Administration, the State of Indiana, or other authorized representatives of any unit providing funding for the project shall be furnished copies thereof if requested.

$$
\text { Sincerely, }
$$




\section{Keys To A Successful Project}

- COMMUNICATE...COMMUNICATE...COMMUNICATE...COMMUNICATE

- Ask questions

- Be engaged in the process

- Take ownership 


\section{Questions?}

